\title{
A Equipe Psicossocial na Colocação da Criança nos Processos de Adoção
}

\author{
Patrícia Santos da Silva \\ Luciana Cassarino-Perez \\ Universidade Federal do Rio Grande do Sul, RS, Brasil. $\quad$ Universidade Federal do Rio Grande do Sul, RS, Brasil. \\ Jorge Castellá Sarriera \\ Giana Bitencourt Frizzo \\ Universidade Federal do Rio Grande do Sul, RS, Brasil. $\quad$ Universidade Federal do Rio Grande do Sul, RS, Brasil.
}

Resumo: Este estudo objetivou investigar e refletir sobre o papel da equipe psicossocial do Judiciário na fase de inserção, ou em termos legais colocação, nos processos de adoção. Foram entrevistados sete psicólogos e 11 assistentes sociais judiciários de sete cidades do Rio Grande do Sul. A partir da análise de conteúdo foi possível constatar que a maioria das colocações são conduzidas pela equipe do Juizado da Infância, com ou sem auxílio da equipe da instituição de acolhimento, e em algumas comarcas conduzidas apenas pelas equipes dessas instituições. Observaram-se também diferenças entre as práticas dos profissionais, ficando os psicólogos mais encarregados dos processos considerados complexos, a exemplo dos casos de adoção tardia. Discute-se a falta de uma metodologia consensuada nesta etapa, bem como o papel do psicólogo apenas nos casos considerados mais difíceis. Também se aponta a importância de se atentar para práticas realmente voltadas para o melhor interesse da criança.

Palavras-chave: Adoção (Criança), Processos Legais, Psicologia Forense.

\section{The Role of The Psychosocial Team in Placing a Child for Adoption}

\begin{abstract}
The aim of this study was to investigate and reflect upon the role of the psychosocial judicial staff in the placement phase of the adoption process. Seven psychologists and 11 judicial social workers, from seven cities in southern Brazil, were interviewed. From the content analysis, it was possible to grasp that while placement in most counties is conducted by the team of Juvenile Court, with or without help from the foster care's staff, in a few counties it is conducted only by teams of foster care. Differences between the practices of professionals were also found, with psychologists in charge of the processes considered more complex, like the late adoption cases. The authors propose reflections about the implications of the differences found on practice, for the role of the psychologist in the placement stage. We conclude that the legal team has a central role in the placement stage, but efforts still need to be employed to achieve a consensual methodology.
\end{abstract}

Keywords: Adoption (Child), Legal Processes, Forensic Psychology. 


\title{
El Equipo Psicosocial en la Colocación del Niño en Adopción
}

\begin{abstract}
Resumen: El objetivo de este estudio fue investigar y reflexionar sobre el rol del equipo psicosocial judicial en la etapa de inserción, o en términos legales 'colocación', en los procesos de adopción. Se entrevistaron siete psicólogos y 11 trabajadores sociales judiciales en siete ciudades del sur de Brasil. A través del análisis de contenido se observó que, en la mayoría de los casos, la colocación es conducida por el equipo judicial, con o sin auxilio del equipo de las instituciones de acogimiento. En algunos casos, el proceso es conducido solamente por las instituciones. También se constataron diferencias entre las prácticas de los profesionales, estando los psicólogos más encargados de los procesos considerados complejos, como los de adopción tardía. Se discuten las implicaciones de las distintas maneras de actuar de los equipos, en lo que se refiere a la práctica del psicólogo en la colocación. Se concluye que el equipo judicial tiene un rol central en la colocación, aunque todavía sean necesarios esfuerzos para alcanzar un método consensual para conducir esa etapa.
\end{abstract}

Palabras clave: Adopción (Niño), Procesos Legales, Psicología Forense.

\section{Introdução}

$\mathrm{O}$ ato de transferir a responsabilidade pelo cuidado de crianças de um adulto para outro acompanha a história da humanidade desde as mais antigas civilizações de que se tem registro (Cide of Hamurabi, 1780a.C.; Coulanges, 1864). Historicamente, esse processo que hoje se denomina "adoção" sempre esteve mais ligado ao interesse dos adultos do que aos direitos e necessidades das crianças e adolescentes (Costa, \& Rossetti-Ferreira, 2007; Fonseca, 2006). No Brasil não foi diferente, a maioria dos processos de adoção não passava pela intervenção do Estado, e o poder público demorou a se organizar para responder às demandas de sistematização e garantia do superior interesse da criança (Nabinger, 2010).

Nas últimas décadas houve uma conscientização das mudanças necessárias, principalmente por parte dos profissionais e instituições ligados ao tema resultando no aumento no número de estudos, relatórios e estatísticas produzidas sobre adoção no país. Esse movimento, somado à pressão por parte da sociedade civil, gerou iniciativas pontuais de alguns serviços e profissionais ligados a municípios e estados, que culminaram na mudança de um paradigma centrado no adulto, para um paradigma centrado no interesse da criança (Nabinger, 2010). Um marco importante na consolidação dessa mudança foi a instituição do Estatuto da Criança e do Adolescente - ECA (Brasil, 1990), em 1990, como instrumento de regulamentação e garantia dos direitos dessa população.

Em seu capítulo V, o ECA define a adoção como uma modalidade de colocação em família substituta que garante plenos poderes parentais aos adotantes, caracterizando-se como último recurso depois de esgotadas as possibilidades de reintegração da criança à família de origem (Brasil, 1990). Além da mudança de paradigma e da regulamentação da prática da adoção, o ECA apresentou outro avanço ao prever a organização dos dados referentes aos processos através da obrigatoriedade da realização de um cadastro por comarca. A sistematização dessas informações avançou ainda mais com a instituição da Lei no 12.010, de 2009 (Brasil, 2009a) que, institui a necessidade dos Cadastros Nacional e Estadual de Adoção, a partir dos quais foi possível unificar os dados e aproximar as crianças que aguardavam por uma família dos candidatos a adotantes.

Além disso, a Lei no 12.010/2009 (Brasil, 2009a) prevê ações que estimulem a chamada "adoção tardia", assim como aquela em que grupos de irmãos sejam adotados juntos. Essa prática vem sendo observada em campanhas "pró-adoção" desenvolvidas recentemente. Porém, de acordo com o Conselho Nacional de Justiça, através de dados do Cadastro Nacional de Adoção, em janeiro de 2016 estavam inscritos 34.535 pretendentes a pais e mães e 6.331 crianças disponíveis para adoção. Embora o número de crianças seja menor do que a de interessados em adotar, o número de adoções realizadas no primeiro semestre de 2015 foi de 625 . Essa realidade se explica em parte pela disparidade entre o perfil de crianças disponível e aquele desejado pelos pretendentes. A idade da criança é um dos aspectos que ilustra essa situação. Enquanto 56\% das inscritas no cadastro têm mais de 12 anos, menos 
de $1 \%$ dos candidatos a adotantes desejam ser pai ou mãe de crianças com essa idade ou mais (Brasil, 2016).

Também estão previstas na legislação diretrizes específicas no que se refere ao processo de habilitação dos pretendentes e a preparação psicossocial dos mesmos, por meio de cursos e programas de orientação, apesar de a lei não estabelecer especificamente o que deve ser trabalhado nesses programas. No que se refere especificamente à fase de colocação de crianças e adolescentes em famílias substitutas, a lei prevê que esta deve incluir processos de preparação gradativa e de acompanhamento posterior. Caberia às equipes multiprofissionais dos Juizados da Infância e da Juventude (JIJ) do país conduzir os processos envolvidos na colocação (Brasil, 2009a).

Os avanços da legislação no que concerne aos processos de adoção também estão atravessados pelas constantes transformações familiares ocorridas nas últimas décadas. A configuração familiar é cada vez mais diversa, com crescente número de adolescentes grávidas, pessoas que optam por conceber e criar filhos sozinhos, filhos de pais separados e recasados, aumento nos casos de infertilidade, famílias homoafetivas, entre outras configurações existentes (Mahl, Jaeger, Patias, \& Dias, 2012; Miranda Júnior, 1998). No trabalho da equipe psicossocial na habilitação de pretendentes à adoção, a complexidade envolvida nos distintos processos pelos quais são responsáveis se apresenta como um desafio para a prática. Ao entrevistar profissionais responsáveis pelos processos de habilitação de candidatos à adoção no estado do Rio Grande do Sul (Silva, 2015), constatou-se que as novas configurações familiares (como casais heterossexuais, recasados e pais solteiros) representam um desafio às práticas profissionais, já que na maioria dos relatos analisados apareceram questões ainda muito ligadas a concepções biológicas de família.

Além dos processos de habilitação, as equipes psicossociais são responsáveis pelo andamento de todas as etapas que dizem respeito ao processo de adoção, desde a destituição do poder familiar, em que a equipe avalia as condições da família para a manutenção ou retirada da criança do contexto de vulnerabilidade, até a inserção da criança de fato na convivência com a família substituta. Esta última etapa, denominada na literatura a área como "colocação", inicia-se com a proposição (momento em que se propõe aos pretendentes quem é a criança a ser adotada através de documentos) e preparação da criança para a apresentação da família. Na sequência, as duas partes são apresentas e passam por um período de adaptação que finalizará com a mudança efetiva da criança ou adolescente para sua nova casa. Inicia-se então o estágio de convivência, período em que a equipe segue acompanhando a família para auxiliar no processo de construção dos vínculos (Nabinger, 2010).

Estudos nacionais e internacionais apontam para a complexidade e importância da etapa de colocação (Alonso, 2012; Levy, Pinho, \& Faria, 2009; Simmel, 2007; Sturgess, \& Selwyn, 2007; Weber, 2003). Esse período é denominado por Costa e Rosseti-Ferreira (2007) como a entrada no "limbo", por se tratar de um momento frágil, de construção de vínculos onde todos os envolvidos sabem da possibilidade da devolução da criança à instituição. A colocação traz consigo a concretização da adoção normalmente implicando em perdas, lutos e rompimentos. É um momento que simboliza a nova filiação e a desvinculação definitiva da criança da sua família de origem (Nabinger, 2010), a ruptura dos laços de convivência com os colegas e cuidadores da instituição de acolhimento (Vargas, 1998), entre outras perdas de vínculos com pessoas com as quais a nova rotina não possibilitará o contato diário. Concomitante às perdas, o período de colocação se caracteriza também pelo início da construção de novos vínculos afetivos e familiares, pois é a partir do que se dará neste momento que uma nova dinâmica familiar começará a ser construída (Alonso, 2012).

Por parte dos pais adotivos, é na colocação que ocorre o encontro com o "filho real" em contraposição à criança idealizada durante tempo de espera pela adoção (Levy et al., 2009). O longo período que normalmente caracteriza um processo de adoção, muitas vezes é vivido com angústia pelos pretendentes. É também uma fase de transição em que não se exerce a parentalidade de fato, embora já se tenha feito a opção por exercer o papel de pai ou mãe. A espera favorece o surgimento de fantasias e questionamentos, é um período em que inevitavelmente os futuros pais imaginam como serão seus filhos, como se dará o vínculo com eles, desencadeando sentimentos permeados por ansiedade e ambivalência (Huber, \& Siqueira, 2010; Reppold, Chaves, Nabinger, \& Hutz, 2005; Weber, 2003).

Quando o novo filho finalmente chega, ele traz consigo um background, que se pode entender metaforicamente como uma "mochila" na qual transporta sua história e seus vínculos anteriores, tão recheada 
de conteúdo quanto maior for a sua idade (Alonso, 2012). Essa "bagagem" não necessariamente corresponderá às idealizações que os pais tiveram tanto tempo para formular. Da complexidade de aspectos envolvidos na chegada de uma criança ou adolescente a uma nova família deriva a necessidade do manejo de comportamentos que serão reflexo de suas trajetórias até aquele momento, comportamentos estes que nem sempre corresponderão às expectativas das famílias (Costa, \& Rossetti-Ferreira, 2007; Levy et al., 2009; Sturgess, \& Selwyn, 2007).

Pela multiplicidade de fatores envolvidos na fase de colocação, autores defendem a existência de um período de convivência que não deve ser apressado, respeitando-se o tempo de cada criança e família (Paiva, 2004; Weber, 2003). Também ressaltam a importância da preparação de ambas as partes, envolvendo o conhecimento prévio das histórias, gostos e hábitos uns dos outros, a fim de estreitar as distâncias e minimizar possíveis frustrações e equívocos decorrentes de expectativas irreais (Alonso, 2012; Costa, \& Rossetti-Ferreira, 2007; Simmel, 2007).

De acordo com Nabinger (2010), o processo de preparação e colocação é único, deve considerar as características pessoais e de contexto, mas também obedecer a certo rigor metodológico, estabelecendo objetivos claros e respeitando etapas de começo, meio e fim. Para a autora, a criança deve passar por uma avaliação prévia à adoção, que fornecerá uma noção geral das suas necessidades para que se possa encontrar uma família adequada a essas demandas.

A segunda etapa seria a preparação da criança para a colocação na família, ao fornecer espaço para a elaboração do luto pela sua história para que se permita o estabelecimento de novos vínculos familiares. A preparação também envolveria uma apresentação da família adotiva através de fotos, cartas e outros recursos. Nesse sentido, a equipe psicossocial do judiciário vem sendo apontada como essencial no acompanhamento do período de colocação, assim como no estágio de convivência que se segue (Merçon-Vargas, Rosa, \& Dell'Aglio, 2014; Nabinger, 2010; Weber, 2003).

Sobre o estágio de convivência, a lei não estabelece um tempo determinado para a sua duração, ficando a equipe técnica a cargo de avaliar as necessidades de cada caso especificamente (Hamad, 2002; Levinzon, 2014; Nabinger, 2010). Ghesti-Galvão (2008) afirma que o agente psicossocial deve funcionar, em todas as etapas desse processo, como um media- dor entre o afeto e a lei, promovendo acolhimento, informação e formação às pessoas interessadas em adotar, entendendo que dessa forma será possível promover mudanças nas idealizações, representações e comportamentos. Alguns estudos também têm apontado a importância do vínculo com as equipes para um desenvolvimento saudável dos vínculos da nova família (D’Andrea, 2002). A qualidade das informações recebidas e a maneira como são conduzidos os processos parecem influenciar a construção da parentalidade adotiva (Ryan, \& Whitlock, 2008). Nabinger (2010) aponta que todo o processo de adoção e, principalmente, a colocação em família substituta exige muito dos profissionais ligados aos JIJ. Isso porque a tarefa extrapola o trabalho pericial e avaliativo realizado normalmente, em que o laudo é o objetivo principal (Rovinski, 2007). A colocação exige um caráter interventivo em que a qualidade do vínculo estabelecido entre equipe e família adotiva é uma questão extremamente importante. Com isso, os profissionais precisam ter o cuidado de estabelecer uma prática constante, para evitar repetir rupturas, separações e perdas já tão frequentes (Nabinger, 2010).

Embora existam diversos estudos no Brasil apontando a importância do acompanhamento e da preparação para adoção por parte da equipe psicossocial do judiciário, muito pouco se têm pesquisado sobre a forma como os processos de fato são conduzidos por esses profissionais nos Juizados de Infância e Juventude (JIJ). Especificamente em relação à fase de colocação, observa-se ainda maior escassez de produção técnica que possa respaldar a atuação. Faz-se necessário compreender como essa etapa do processo de adoção vem ocorrendo e de que forma podemos aprimorar sua realização. Nesse sentido, o objetivo deste estudo foi investigar e refletir sobre o papel da equipe do judiciário na fase de colocação nos processos de adoção em diferentes comarcas do estado do Rio Grande do Sul.

\section{Método}

\section{Participantes}

Participaram do estudo sete psicólogos e 11 assistentes sociais judiciários de sete cidades do estado do Rio Grande do Sul. A seleção dos participantes para a composição da amostra se deu a partir do contato via e-mail com todos os profissionais da Psicologia e do serviço social do Tribunal de Justiça do Rio Grande do Sul. Os contatos foram obtidos a partir dos grupos 
de estudos de cada classe profissional, organizados por eles próprios. Todos os profissionais que responderam ao contato se disponibilizaram a participar da pesquisa e os que tiveram autorização do juiz da comarca foram entrevistados.

Os participantes atuavam nos Juizados da Infância e da Juventude de suas comarcas e atuavam nas medidas de proteção, dentre elas a adoção. Os participantes eram formados há um período médio de 24 (DP $=7,13$ ) anos e trabalhavam no judiciário há uma média de $14(\mathrm{DP}=9,65)$ anos, tendo no mínimo 4 meses e no máximo 28 anos de experiência no judiciário. As mulheres representaram $94 \%$ dos participantes.

No que se refere à formação, seis psicólogos possuíam curso de especialização nas áreas Psicologia Clínica de abordagem psicanalítica, Psicologia Clínica de abordagem sistêmica, Avaliação Psicológica, Psicologia Jurídica e Criminologia. Apenas um possuía mestrado em Psicologia. Dentre os profissionais do Serviço Social, cinco possuíam curso de especialização sendo as áreas: Terapia de Família (quatro profissionais) e Metodologia do Ensino Superior.

Dentre as sete comarcas investigadas, duas delas contavam com somente um profissional na equipe técnica no momento da entrevista (em uma delas um psicólogo e na outra um assistente social). Em outras quatro comarcas, havia somente um psicólogo lotado, e, em três dessas, os profissionais atendiam, além de processos da vara da infância e juventude, processos de outras varas como família e criminal. Apenas em uma das comarcas investigadas a equipe era composta por mais de um psicólogo e mais de um assistente social, havendo uma diferenciação no trabalho realizado por esses profissionais. Nesta comarca, havia três varas da infância e da juventude, sendo que os técnicos entrevistados atendiam somente processos que envolviam medidas de proteção à criança e ao adolescente, dentre elas a adoção. Estes dados podem ser observados na Tabela 1.

\section{Delineamento e procedimentos}

Este estudo foi parte de um projeto maior intitulado "Estar apto a ser pai e mãe adotivo do ponto de vista jurídico" (Silva, 2015) que teve como objetivo compreender as práticas de psicólogos e assistentes sociais jurídicos do Rio Grande do Sul e das outras regiões do país nos processos de adoção e habilitação para adoção. Para este artigo, utilizou-se um delineamento qualitativo exploratório (Robson, 2002), atra-
Tabela 1

Dados descritivos das comarcas em função dos profissionais que compõem a equipe.

\begin{tabular}{lcc}
\hline \multirow{2}{*}{ Comarca } & \multicolumn{2}{c}{ Profissionais que compõem a equipe } \\
\cline { 2 - 3 } & Psicólogo & Assistente Social \\
\hline 1 & 1 & 0 \\
2 & 0 & 1 \\
3 & 1 & 1 \\
4 & 1 & 1 \\
5 & 1 & 4 \\
6 & 1 & 1 \\
7 & 4 & 10 \\
\hline
\end{tabular}

vés do depoimento dos profissionais, com objetivo de conhecer a sua prática nos processos de adoção e habilitação para adoção.

Primeiramente, os profissionais foram contatados por e-mail a fim de se verificar o interesse e a disponibilidade em participar da pesquisa. Após a ciência e concordância dos juízes com a participação do profissional, mediante assinatura do "Termo de ciência do responsável pelo local onde será realizada a pesquisa", fez-se o agendamento das entrevistas nos locais de trabalho dos participantes. Os profissionais responderam a duas entrevistas, individualmente, após a assinatura do "Termo de consentimento livre e esclarecido".

\section{Instrumentos}

A primeira entrevista foi uma "Entrevista de dados profissionais", que abordou temas relacionados à formação profissional, ao tempo de trabalho na comarca, aos tipos de processos atendidos e ao incentivo à capacitação profissional percebido pelo participante. A segunda entrevista teve duas versões, uma para psicólogos e outra para assistentes sociais, a fim de abarcar eventuais especificidades no trabalho desses profissionais: "Entrevista sobre o processo de habilitação para adoção - versão psicólogos e versão assistentes sociais". Ambas consistiam em uma entrevista semiestruturada, elaboradas para este estudo, que abordaram temas referentes ao fluxo dos processos em cada comarca, participação dos profissionais nos processos, avaliação de candidatos à adoção conforme a especialidade profissional, critérios utilizados e como os candidatos eram preparados. 


\section{Considerações éticas}

O estudo seguiu os princípios éticos da pesquisa com relação à proteção dos direitos, bem-estar e dignidade dos participantes, como apontado na Resolução № 466 de 2012, do Conselho Nacional de Saúde. O projeto foi aprovado pelo Comitê de Ética em Pesquisa do Instituto de Psicologia da Universidade Federal do Rio Grande do Sul. Os profissionais que se dispuseram a participar do estudo e foram autorizados pelo respectivo juiz, através do "Termo de ciência do responsável pelo local onde será realizada a pesquisa” e assinaram o "Termo de consentimento livre e esclarecido".

\section{Análise dos dados}

As entrevistas foram gravadas em áudio digital e transcritas posteriormente. Os dados provenientes das entrevistas foram analisados por meio da análise de conteúdo (Bardin, 2011; Laville, \& Dione, 1999) e as categorias foram construídas a partir da leitura dos dados. A análise foi realizada com o auxílio do software QSR NVivo versão 10 ("NVivo Qualitative Data Analysis Software [Version 10]," 2012).

O objetivo da análise foi identificar as práticas dos profissionais na etapa de colocação da criança nos processos de adoção. A partir da leitura, foi possível identificar três grandes categorias: A equipe do JIJ e suas funções; Procedimentos de colocação; e Análise avaliativa dos profissionais.

\section{Resultados}

Em relação às práticas dos profissionais na etapa de colocação da criança nos processos de adoção, foi possível perceber que há diferenças entre as equipes. Observou-se que a diversidade de práticas se dá principalmente no funcionamento das comarcas investigadas. A partir disso, foi possível categorizar os dados a partir das funções da equipe técnica na etapa de colocação da criança, das principais práticas nos processos de adoção e da visão dos mesmos sobre os procedimentos ${ }^{1}$ realizados.

\section{Procedimentos de colocação}

As práticas adotadas pelos profissionais na etapa de colocação das crianças diferem de acordo com a comarca em que se localizam e, em alguns casos, dentro de uma mesma equipe. Porém, através do relato de alguns entrevistados, foi possível observar que, a partir da experiência, algumas comarcas definiram práticas a serem adotadas em todos os casos e, salvo por pequenas diferenças, elas costumam estar organizadas em três momentos distintos. A Tabela 2 apresenta essas três etapas, quais são as comarcas que as realizam e quais os profissionais responsáveis por cada uma delas.

O primeiro deles, realizado na maioria das vezes pelos assistentes sociais, é o de apresentação da criança disponível para adoção aos candidatos, através de documentos e informações que descrevam suas características (o que os profissionais denominam de "dossiê" da criança). Esta etapa tem como objetivo definir se os candidatos têm, de fato, interesse na adoção daquela criança específica, antes de propor um encontro com ela. Percebe-se na fala dos entrevistados uma preocupação em não criar expectativas na criança que espera pela adoção, aguardando a confirmação de que de fato os pretendentes darão seguimento ao processo: "Em caso de crianças maiorzinhas, a gente toma o cuidado de primeiro chamar a equipe do abrigo e os pretendentes, conversar, mostrar fotos para eles terem certeza, para não expor as crianças a uma falsa expectativa” (AS2).

O segundo momento é o de preparação da criança para conhecer aquela determinada família. As práticas relatadas nesse momento são muito influenciadas pela idade e pelas características das crianças que deverão ser preparadas. Além disso, foi apontada como uma prática mais realizada pelos psicólogos, principalmente nos casos de adoção tardia (o que ainda são considerados mais complicados pelas equipes):

Então, a gente chama e começa a preparação para a adoção, para a criança também saber desses pais através de nós. Acho que isso é importante, a gente vai criando um espaço interno de representação, tanto nos pais, quanto na criança, e não só o concreto, de aproximar, de entregar a criança. Vai conhecendo esses pais, imaginando eles também. Não demora muito tempo, senão a criança fica na ansiedade de conhecer. Então, fazemos algum contato e se combina, de acordo

\footnotetext{
${ }^{1}$ Enfatiza-se que os dados das entrevistas dos psicólogos e dos assistentes sociais foram analisados conjuntamente porque, em um primeiro momento, não se observaram diferenças importantes nas práticas relatadas. As diferenças existentes foram discutidas mais profundamente na sessão de discussão.
} 
Tabela 2

Descrição dos procedimentos e de quem os realiza em cada comarca.

\begin{tabular}{|c|c|c|c|c|c|}
\hline \multirow[b]{2}{*}{$\begin{array}{l}\text { Realização dos } \\
\text { procedimentos }\end{array}$} & \multirow[b]{2}{*}{$\begin{array}{c}\text { Etapa } 1 \\
\text { Apresentação } \\
\text { por } \\
\text { documentos } \\
\text { da criança } \\
\text { aos adotantes } \\
\text { (proposição) }\end{array}$} & \multicolumn{2}{|c|}{ Etapa 2} & \multicolumn{2}{|c|}{ Etapa 3} \\
\hline & & $\begin{array}{c}\text { Preparação da } \\
\text { criança para } \\
\text { apresentação } \\
\text { aos adotantes }\end{array}$ & $\begin{array}{l}\text { Preparação da } \\
\text { instituição de } \\
\text { acolhimento }\end{array}$ & $\begin{array}{c}\text { Primeiro } \\
\text { contato entre } \\
\text { criança e } \\
\text { adotantes }\end{array}$ & $\begin{array}{c}\text { Período de } \\
\text { adaptação } \\
\text { antes da } \\
\text { mudança para } \\
\text { a nova casa }\end{array}$ \\
\hline $\begin{array}{l}\text { Por ambos os profissionais } \\
\text { em conjunto }\end{array}$ & 1,3 & 1,3 & 1,3 & 1,3 & 1 \\
\hline Pelo psicólogo & 4 & - & 4,5 & 4,5 & - \\
\hline Pelo assistente social & $2,5,6$ & - & $2,4,6$ & $2,4,6$ & - \\
\hline $\begin{array}{l}\text { Pelo psicólogo quando } \\
\text { adoção tardia }\end{array}$ & 7 & 7 & 7 & 7 & 7 \\
\hline Equipe do JIJ não participa & - & $2,4,5,6$ & - & - & $2,3,4,5,6$ \\
\hline
\end{tabular}

Nota: Os números identificam cada comarca, conforme Tabela 1.

com o caso, um primeiro encontro, ou na instituição, ou no juizado (PSI2).

Algumas técnicas, como o uso de fotos e de materiais confeccionados pela família, foram relatadas como importantes para a preparação das crianças:

Então aí já começa a trabalhar: peço para o casal montar um material que ele queira, da forma que ele queira, que use da criatividade, da emoção, mas que ele mostre um pouco da pessoa que ele é, da casa que ele mora [...] Uns montam álbum, uns montam histórias, criam livros... Aí vai de cada casal. E dentro disso tem as fotos: foto do casal, foto da casa, das peças... E paralelamente tu tá trabalhando com a criança: "olha, encontrei uma família pra ti. É assim, tem pai, tem mãe, ou não tem..." E a criança também, paralelamente, prepara material pra esse casal. Desenhos... Alguma coisa que elas queiram. Aí, esse material pronto de cada um, tu começa a transitar pra lá e pra cá. O que um fez fica com ele. E vai indo... Até a criança tá pronta pra conhecer o casal (PSI7).

Também aparece como relevante neste segundo momento a preparação da equipe da instituição de acolhimento para o acompanhamento da etapa seguinte, de aproximação. Já o terceiro momento identificado diz respeito à fase de encontro e adaptação da criança com os pais adotivos. Aqui se identificou importante influência do perfil e da idade da criança nas práticas adotadas pelos profissionais. Novamente nesta etapa, o trabalho do psicólogo aparece associado aos casos de maior complexidade ou de adoção tardia.

\section{A equipe do JIJ e suas funções}

Participação nos processos de colocação

Nas comarcas em que havia poucos profissionais, o auxílio das equipes das instituições de acolhimento foi relatado como fator importante para o trabalho. Já onde havia mais profissionais ligados ao judiciário, a equipe técnica pareceu envolver-se mais na etapa de colocação da criança. Com isso, observou-se que há casos em que a colocação é realizada somente pela equipe do JIJ, pela equipe do JIJ em conjunto com a equipe da instituição de acolhimento ou somente pela equipe da instituição de acolhimento.

A maioria dos profissionais (12) relatou que o trabalho de colocação da criança é realizado basicamente pela equipe do judiciário, composta normalmente por psicólogos e assistentes sociais. Eles são responsáveis por todas as etapas do processo: preparação da criança e apresentação aos pretendentes, acompanhamento direto na fase de adaptação até o desligamento da criança e a ida para a casa dos pais. Nessas falas, foi possível identificar que em algumas comarcas havia divisão de tarefas entre psicólogos e assistentes sociais e, em outras, o trabalho era realizado em conjunto, conforme o Quadro 1. 
Quadro 1

Funções da equipe técnica do JIJ.

\begin{tabular}{|c|c|c|c|}
\hline \multirow{2}{*}{ Comarca } & \multicolumn{2}{|c|}{ Forma como o trabalho é realizado } & \multirow{2}{*}{ Função da equipe do JIJ na colocação } \\
\hline & Em equipe & Individualmente & \\
\hline 1 & & $\mathrm{X}$ & Realizam todo o processo \\
\hline 2 & & $\mathrm{X}$ & Somente a aproximação ${ }^{a}$ \\
\hline 3 & $\mathrm{X}$ & & Somente a aproximação ${ }^{a}$ \\
\hline 4 & & $\mathrm{X}$ & Somente a aproximação ${ }^{a}$ \\
\hline 5 & $\mathrm{X}$ & & Somente a aproximação ${ }^{\mathrm{a}}$ \\
\hline 6 & & $\mathrm{X}$ & Realizam todo o processo \\
\hline 7 & Varia de acord & $\begin{array}{l}\text { finidade entre os } \\
\text { nais }\end{array}$ & Varia de acordo com cada profissional \\
\hline
\end{tabular}

Nota: a'Os profissionais participam somente da aproximação entre os adotantes e a equipe da instituição de acolhimento. A equipe do JIJ participa da preparação dos adotantes e toda a preparação da criança fica a cargo da equipe da instituição de acolhimento.

Alguns profissionais (8) relataram haver uma divisão do trabalho em função da idade da criança que a ser adotada. Nos casos dos bebês até três anos, o trabalho seria realizado somente pelo assistente social. Já o trabalho em equipe, de forma interdisciplinar, apareceu somente como uma solução aos casos considerados mais graves, não sendo uma prática comum em algumas comarcas:

Aqui, em [nome da cidade], em termos de critério de fluxo de trabalho, até os três anos de idade, as crianças são atendidas exclusivamente pelas assistentes sociais, salvo quando identificada alguma desarmonia, alguma questão relevante que precise de uma abordagem interdisciplinar (PSI3).

Tanto psicólogos quanto assistentes sociais relataram que o trabalho da Psicologia se faz necessário nos casos que consideram mais complexos, como as adoções tardias:

O que é mais difícil, que é o que a gente precisa da parceira da Psicologia, é quando a criança é maior (AS1).

Se necessário, se achar que é uma criança com que possa ser mais difícil a adoção, se chama o psicólogo e se faz a adoção junto (PSI2).

Outra questão que pareceu influenciar a forma como as tarefas são distribuídas foi a organização já estabelecida na comarca, apesar de ambos os profis- sionais estarem capacitados para realizar o trabalho. Já outro profissional afirmou que a Psicologia seria mais requisitada no acompanhamento da criança, ficando os assistentes sociais mais ocupados do contato com os candidatos: "Mas ficava sempre a criança mais a cargo da Psicologia e o casal mais a cargo do serviço social. Porque o casal também precisa de suporte" (PSI7). Apenas quatro profissionais relataram que o trabalho é realizado sempre em equipe, seja qual for a situação.

Poucos profissionais (2) afirmaram que a colocação da criança acontece de maneira conjunta com a instituição de acolhimento. Os relatos mostraram que a primeira etapa de colocação da criança, o contato com os pretendentes e o encontro entre a criança e os pais, acontecem no JIJ e os passos seguintes se dão com acompanhamento da equipe de acolhimento "O primeiro encontro é aqui, depois segue com o abrigo" (AS2). Apenas um dos profissionais enfatizou a importância de o trabalho ser realizado, principalmente, pela equipe do JIJ sem delegar tantas tarefas para a equipe da instituição de acolhimento.

De acordo com alguns dos entrevistados, essa participação da equipe do JIJ também é importante para que se possa conhecer os candidatos, nos casos em que o processo de habilitação não foi acompanhado por aquele mesmo profissional, e reavaliá-los antes do contato com a criança. Mais de um profissional enfatizou a necessidade da equipe técnica do JIJ estar presente antes da aproximação para que a criança possa ser preparada para a nova família: 
Então, a gente chama e começa a preparação para a adoção, para a criança também saber desses pais através de nós. Acho que isso é importante, a gente vai criando um espaço interno de representação, tanto nos pais, quanto na criança, e não só o concreto, de aproximar, de entregar a criança. Vai conhecendo esses pais, imaginando eles também (PSI2).

Este mesmo entrevistado também afirmou que, no momento do encontro entre a família e a criança, a equipe deve estar presente, atuando como mediadora. Essa conduta facilitaria o encaminhamento e seguimento por parte da equipe de acolhimento: "Já faz, nesse primeiro encontro, também, um contato do casal com alguém da instituição, que fique envolvido, da instituição, o que também dá uma autonomia para ele ir combinando os encontros posteriores, de visitas" (PSI2).

Três profissionais relataram que não sentem a necessidade de que o juizado interfira, pela existência de equipes capacitadas nas instituições de acolhimento. Com isso, a função dos técnicos do JIJ acaba sendo de receber os relatórios e avaliar se a situação está se desenvolvendo bem.

Teve um período em que a gente acompanhava muito mais isso. Eu, pessoalmente, não tenho feito. Não só pelo tempo, mas é que eu não acho que é o mais importante, acho que tem outras formas que a gente pode fazer e, felizmente, algumas instituições têm boas equipes e isso ajuda muitíssimo (PSI2).

Percebe-se que, embora sejam apenas três do total de profissionais entrevistados, ainda existe a compreensão por parte de alguns deles de que as equipes do judiciário não devem centralizar o acompanhamento da fase de colocação.

Reflexões dos profissionais acerca do trabalho em equipe

Um aspecto interessante que emergiu nas falas dos profissionais foi a importância atribuída por eles ao trabalho em conjunto, principalmente entre psicólogos e assistentes sociais integrantes da mesma equipe técnica. Em alguns relatos o trabalho interdisciplinar foi apontado como fundamental, especialmente nos casos de maior complexidade, citando novamente os casos de adoções tardias: "Vai depender da dupla. Tem umas que gostam de trabalhar em conjunto, outras não, que preferem trabalhar sozinhas, separadas, o que eu acho bem complicado" (AS1). Nesta e em outras falas, foi possível observar que a interdisciplinaridade se dava muito mais em função da afinidade existente entre os profissionais do que pela percepção da necessidade de um trabalho integrado.

Em algumas comarcas o discurso dos profissionais revelou a importância atribuída ao trabalho em equipe, porém a ausência de afinidade pareceu impedir que a colaboração acontecesse. No entanto, mesmo nessas situações em que a troca não ocorria de forma constante e mais aprofundada, houve relatos de alguns profissionais buscando dialogar com os colegas:

[quando] tu vais chamar um pretendente que tu nunca viste na tua frente, tu só vais ter acesso ao laudo. Eu busco fazer isso: vou conversar com a colega que fez a avaliação, vou pedir mais informações além do que está no papel. Vou pedir a opinião dela: "O que tu achas? Estou com uma criança assim, assado, uma criança que tem uma história de violência... O que tu achas que esse casal, como tu achas que o casal vai lidar com isso?" É o mínimo que se pode fazer, mas é difícil (AS9).

Outro aspecto relevante foi a existência ou não de divisão de tarefas dentro da mesma equipe a partir da expertise de cada área. Por vezes, a sincronia na execução do processo era tão grande que as funções acabam se sobrepondo e os psicólogos e assistentes sociais acabavam percebendo semelhanças em suas práticas.

\section{Análise avaliativa dos profissionais}

Foi interessante observar que, ao relatarem sobre o funcionamento da etapa de colocação, os técnicos apontaram questões que refletiram a importância atribuída ao trabalho que realizam. Além disso, levantaram diversos aspectos em que o trabalho poderia ser diferente. As percepções sobre o processo foram divididas em aspectos positivos e aspectos negativos, apresentados de forma resumida no Quadro 2. 
Quadro 2

Análise avaliativa dos profissionais que atuam ativamente na etapa de colocação.

\begin{tabular}{|c|c|}
\hline Aspectos positivos & Aspectos negativos \\
\hline $\begin{array}{l}\text { Reconhecimento e } \\
\text { gratificação }\end{array}$ & $\begin{array}{c}\text { Demanda excessiva de } \\
\text { trabalho }\end{array}$ \\
\hline $\begin{array}{l}\text { Vinculação com as } \\
\text { famílias }\end{array}$ & $\begin{array}{l}\text { Falta de celeridade nos } \\
\text { processos }\end{array}$ \\
\hline \multirow[t]{3}{*}{$\begin{array}{l}\text { Constatação da } \\
\text { importância do próprio } \\
\text { trabalho }\end{array}$} & $\begin{array}{l}\text { Mudanças constantes } \\
\text { de estrutura e } \\
\text { funcionamento das } \\
\text { equipes }\end{array}$ \\
\hline & $\begin{array}{c}\text { Falta de procedimentos } \\
\text { padronizados }\end{array}$ \\
\hline & $\begin{array}{c}\text { Necessidade de } \\
\text { cumprimento de prazos } \\
\text { e metas }\end{array}$ \\
\hline
\end{tabular}

Aspectos positivos

Diversos profissionais demonstraram que atribuíam à fase de colocação uma função importante no sucesso do processo de adoção como um todo. Observou-se, nas equipes que relataram trabalhar de forma ativa na fase de colocação, o estabelecimento de um vínculo intenso com as famílias adotantes. Em função dessa proximidade, muitos pais e mães continuavam procurando o juizado mesmo após o fim do estágio de convivência para contar sobre as experiências com seus filhos. A manutenção desse vínculo foi apontada pelos entrevistados como gratificante e positiva.

A respeito do sucesso da adoção alguns profissionais referiram que a preparação dos pretendentes e da criança, a aproximação gradativa de ambas as partes e $o$ acompanhamento da equipe durante todo o processo é fundamental para alcançar um desfecho positivo. A preocupação com a fase de colocação e com a preparação dos candidatos parece refletir não só a importância atribuída ao seu trabalho para o sucesso da adoção, como também a responsabilidade conferida à função que cumprem: "Semana passada a colega do abrigo disse pra mim: 'nossa, como tu és cuidadosa de saber como o casal está se sentindo, se eles estão inseguros ou não!', e eu disse: 'a responsabilidade de uma adoção não é só deles que estão levando a criança, é nossa também!" (AS9).

\section{Aspectos negativos}

A respeito do que poderia melhorar em relação às práticas da equipe psicossocial no judiciário, a principal questão levantada pelos profissionais foi a grande demanda de trabalho. Segundo os profissionais, em função da falta de celeridade dos processos no sistema de justiça, por vezes as adoções acontecem antes de concluído o processo de destituição do poder familiar e isso foi relatado como algo bastante negativo.

Especificamente sobre o volume de processos de que cada um precisa dar conta, o excesso de demanda sob responsabilidade de um mesmo profissional foi apontado como um empecilho na qualidade dos resultados almejados pelos mesmos:

Só que, assim, o trabalho está muito "capenga". Eu gostaria de acompanhar esse casal quinta, sexta. Não consegui por causa da minha agenda. Então, o que eu tento fazer - o que, daí, é um tapa-buraco, tapa-furo - é [acompanhar] no telefone. Como hoje: hoje ia ser o primeiro dia em que a menina ia para a casa com eles, para conhecer o espaço, passar o dia com o casal e voltar para o abrigo no final da tarde. Eu sempre fazia isso junto. Não consegui, porque a minha tarde está lotada de atendimentos. Então, é uma readequação que eu fiz, durante vinte e oito anos, numa outra realidade e que, às vezes, incomoda (AS9).

As mudanças no funcionamento das equipes em decorrência das frequentes trocas de juízes, também pareceram influenciar a forma como os profissionais percebem sua prática: "Hoje, a gente trabalha sob pressão em todos os processos. A gente trabalha com prazos, o que, antigamente, não existia. Então, são vários denominadores que acabam nisso que eu estou te dizendo, que eu acho que desqualificou o trabalho..." (AS9). Da mesma forma, foi relatado que as constantes mudanças refletem na falta de procedimentos padronizados que acabam fazendo com que as práticas sejam muito diversificadas, ainda que dentro de uma mesma equipe.

\section{Discussão}

Através das entrevistas realizadas foi possível compreender como ocorre na prática a fase de colocação da criança no processo de adoção nesse contexto. $\mathrm{O}$ aspecto geral que mais se destacou foi a ausência de consenso no que se refere: à forma como a colocação deve ser conduzida, à participação da equipe do JIJ no processo e ao papel dos diferentes profissionais nesta etapa. 
A legislação atual prevê tanto a obrigatoriedade da preparação e colocação da criança, quanto a função central da equipe psicossocial do JIJ nesse processo (Brasil, 2009a). Em 2006, o Ministério Nacional de Desenvolvimento e Combate à Fome, através de instituições ligadas à defesa dos direitos da criança e do adolescente, desenvolveu o Plano Nacional de Convivência Familiar e Comunitária (PNCFC). $\mathrm{O}$ documento propõe, dentre outras metas a serem alcançadas até 2015, a formulação de uma metodologia consensuada entre o JIJ e as instituições de acolhimento para a apresentação da criança aos pretendentes, respeitando o tempo e o entrosamento gradual de ambas as partes (Brasil, 2006).

Em algumas comarcas foi possível identificar o esforço por parte das equipes em organizar a fase de colocação em etapas. Nesses casos as etapas são conduzidas respeitando-se as características e idade dos envolvidos, assim como proposto pelo PNCFC e por Nabinger (2010). Porém na maioria dos casos investigados, apesar da legislação prever a necessidade de uma metodologia consensuada, observou-se que as práticas estão dissociadas. O trabalho é dividido em tarefas muitas vezes não integradas e que nem sempre são realizadas pelos mesmos profissionais, ocasionando a falta de continuidade em muitos processos.

$\mathrm{O}$ fato de não existir um protocolo de atuação implica também na falta consenso sobre o papel do psicólogo e do assistente social nesse contexto. Os relatos demonstraram uma sobreposição das funções e a perda da contribuição específica de cada formação. Observou-se ainda a uma resistência por parte de alguns profissionais para trabalhar em equipe e constituir uma prática interdisciplinar. De acordo com Schneider, Souza, Nasi, Camatta e Machineski (2009), para que exista um trabalho interdisciplinar, é necessário que os profissionais estabeleçam uma relação dialógica sobre as práticas e as rotinas de trabalho. A justificativa oferecida pela maioria dos profissionais que trabalham de forma isolada foi a falta de entrosamento entre os membros da equipe. Mais uma vez, argumenta-se que a uma metodologia consensuada poderia favorecer o processo de colocação, já que esta permitiria superar a falta de entrosamento das equipes, favorecendo relações dialógicas nas práticas de trabalho.

Ainda no que se refere aos psicólogos e assistentes sociais que exercem seu trabalho de forma isolada, cabe ressaltar que, em muitos casos, essa situação não ocorre por escolha deles, mas por obrigação, já que em algumas comarcas as equipes de apoio ao magistrado contam com apenas um dos profissionais. A legislação prevê a existência da equipe mínima, composta por um psicólogo e um assistente social (Brasil, 2009b). No entanto, o último levantamento nacional realizado nestes serviços revelou que essa não é a realidade. Mais da metade (52\%) dos serviços do país não possuía equipe técnica (composta minimamente por psicólogo e assistente social) à época da realização do levantamento (Assis, \& Farias, 2011).

Mesmo em algumas comarcas que contam com profissionais preparados para acompanhar a fase de colocação, observou-se que há casos em que as equipes do JIJ optam por não se envolver ativamente nessa etapa. O corte do vínculo estabelecido entre os profissionais e os adotantes pode ser prejudicial para o processo. Nesse sentido, entende-se como fundamental que a etapa possa ser conduzida pela equipe do judiciário, com auxílio dos profissionais da instituição de acolhimento que possuem maior conhecimento sobre a história e o perfil da(s) criança(s) envolvida(s). A realização desse importante processo somente pela equipe das instituições de acolhimento contribui para uma precarização do trabalho das equipes do JIJ, já que diminui, por exemplo, a necessidade de novas vagas para psicólogos e assistentes sociais no judiciário.

No que se refere especificamente à prática do profissional psicólogo no contexto da colocação da criança ou adolescente em adoção, cabem algumas reflexões. Observou-se no discurso de diversos profissionais a convicção de que o psicólogo deveria ocupar-se especialmente dos casos que envolvessem uma complexidade maior daquela diariamente enfrentada nos processos. Esta concepção do papel do psicólogo pode ter origens na história da inserção deste profissional na área jurídica no Brasil. Segundo Lago, Amato, Teixeira, Rovinski e Bandeira (2009), a aproximação da Psicologia com o direito se deu através da área criminal, onde os psicólogos eram chamados para as avaliações dos casos em que havia dificuldade do juiz. É possível que a prática tenha mantido este padrão de conduta, embora com o passar dos anos as possibilidades de atuação do psicólogo no contexto jurídico tenham se ampliado.

Possivelmente enraizada nas práticas atuais do psicólogo judiciário, é necessária uma reflexão sobre a sua função nos casos de adoção, que tanto diferem daqueles da área criminal. Miranda Júnior (1998) alerta, ao referir-se à função da Psicologia nas Varas, que a 
adoção não é um "processo tão simples quanto quer o suposto humanismo caritativo" (Miranda Júnior, 1998, p. 32). A complexidade de qualquer processo de adoção envolve, minimamente, localizar o lugar do filho adotado dentro de uma constelação simbólica formada pela criança, pelos pais e pela família extensa (Sprince, Hindle, \& Shulman, 2008). Cabe ao psicólogo, com sua formação específica, escutar todas as partes e contribuir para que a criança encontre lugar no seu novo lar, e a família possa recebê-la em seu meio. Este trabalho que antecede a concretização da relação paterno-filial é de extrema importância para evitar uma transição descuidada, inclusive em casos aparentemente "menos complexos", mas que futuramente podem se caracterizar como aqueles em que o princípio do melhor interesse da criança não será atendido.

Uma nova concepção sobre a atuação dos psicólogos nos casos de adoção passa certamente pela formação destes profissionais. Por ser a Psicologia Jurídica uma área considerada emergente no Brasil (Costa, Penso, Legnani, \& Sudbrack, 2009), ela ainda não se caracteriza como uma disciplina oferecida amplamente nos cursos de graduação que contam com currículo generalista (Carvalho, \& Sampaio, 1997; Lago et al., 2009). Nesse sentido, é possível que muitos profissionais que atuam nesta área trabalhem somente com algumas noções sobre os temas, sem um preparo específico (Silva, 2003) como apontaram estudantes do último ano de graduação em Psicologia na pesquisa realizada por Gondim (2002).

Também é verdade que, por parte do Tribunal de Justiça, não existe uma exigência de especialização ou formação nas questões forenses e judiciárias para que se possa compor o quadro. Estudo realizado por Silva (2015) revelou que, mesmo após ingressarem aos cargos por meio de concurso público, os profissionais não recebem incentivo financeiro e/ou de dispensa profissional para dar continuidade a sua formação e aperfeiçoamento técnico. Além disso, os resultados deste estudo demonstram que as áreas de especialização são variadas e nem sempre estão de acordo com as demandas da função exercida. Estes são dados que demonstram o despreparo de alguns profissionais e do próprio sistema de justiça para lidar com demandas tão complexas como o estabelecimento de vínculos em uma família por adoção. É necessário atentar para fato de que as existências impostas legalmente, não garantem que o trabalho esteja sendo realizado com qualidade.
Além da falta de consenso nos processos de colocação e da função específica do psicólogo nesse contexto, um último aspecto que emergiu das falas dos participantes e precisa ser discutido, refere-se ao princípio do melhor interesse da criança e se ele está sendo de fato empregado na etapa de colocação. Alguns profissionais demonstram descontentamento por não conseguirem realizar um trabalho aprofundado no contato entre criança e adotantes. Estes participantes estão cientes da importância dos processos que conduzem, e buscam técnicas para conduzi-los da melhor forma possível. São os casos das comarcas em que os profissionais orientam familiares e criança a trocar fotos e outros materiais, revelando o cuidado com as novas famílias que estão se formando e a compreensão de que é necessário que os vínculos se estabeleçam desde o primeiro contato de maneira segura e saudável.

No entanto, em várias comarcas, a etapa de aproximação da criança para com a nova família não recebe um cuidado especial por parte dos profissionais. Otuka, Scorsolini-Comin e Santos (2012) enfatizam a ideia de que uma adoção "suficientemente boa" não deve ser compreendida apenas como um evento bem-sucedido de inserção da criança em outro lar, mas como um longo processo de identificação, enriquecimento e transformação da família que se constitui. Para que seja possível esta conexão, é fundamental que os profissionais estejam cientes da importância do seu trabalho como uma forma de oferecer apoio a essas famílias em formação (Ghesti-Galvão, 2008). A importância do envolvimento da equipe com a nova família também foi apontada por Ghesti-Galvão (2008) ao tratar da necessidade de mediação entre o afeto e a lei nos casos atendidos nos JIJ.

De acordo com Barboza (2000), o princípio do melhor interesse da criança foi plenamente incorporado pelo ordenamento jurídico, embora, em termos práticos, na maioria dos casos essa premissa continue sendo violada. A autora considera que a efetivação do melhor interesse da criança depende do trabalho interpretativo, de um constante observar sobre qual o modo mais seguro de garantir os direitos desses cidadãos, através de uma preocupação que ultrapassa os aspectos jurídicos, caracterizando-se como um amplo problema político. Nessa tarefa de colocar em movimento um postulado jurídico para conferir-lhe efetividade, é que devem posicionar-se os profissionais da equipe psicossocial. Entende-se o cuidadoso processo de colocação da criança em família substi- 
tuta como uma possibilidade de garantir a efetivação do princípio do melhor interesse da criança.

Por fim, observa-se a necessidade de repensar as práticas e o posicionamento dos profissionais da equipe psicossocial no contexto jurídico, oferecendo espaços de reflexão e formação para estes profissionais. Também é importante que se constitua uma efetiva mudança de paradigma que elimine a possibilidade de uma atuação ultrapassada, centrada nas tarefas e com objetivo principal de simplesmente reduzir o número de crianças abrigadas (Rizzini, \& Rizzini, 2004) Esta mudança deveria passar, inclusive, pela reflexão sobre os termos utilizados para designar os processos, que em parte denunciam o fazer mecânico adotado no sistema judiciário. O termo "colocação" denota a posição objetificada oferecida a criança, contrapondo-se fortemente a compreensão desta como sujeito com direitos e necessidades a serem considerados.

\section{Considerações finais}

O presente estudo investigou e propôs reflexões sobre o papel dos técnicos judiciários do Rio Grande do Sul na etapa de colocação da criança nos processos de adoção. Observou-se que, nesse contexto, as práticas estão dissociadas, faltando uma metodologia consensuada entre as comarcas e dentro das próprias equipes. Também se constatou que, na condução da etapa de colocação, o princípio de melhor interesse da criança nem sempre é considerado, algo que o próprio termo utilizado para designar a etapa já denuncia. Nesse sentido, a realidade constatada ainda se encontra distante do que está estabelecido por lei e do que foi proposto no Plano Nacional de Convivência Familiar e Comunitária como metas para o ano de 2015 (Brasil, 2009b).

Em termos de limitações entende-se que este estudo tratou de uma realidade específica ao investigar somente comarcas do Rio Grande do Sul, não permitindo a generalização dos resultados encontrados. Da mesma forma, compreende-se que abordar somente a visão dos técnicos a respeito das suas próprias práticas pode ter limitado a compreensão do fenômeno. Estudos futuros que possam abarcar a realidade das demais regiões brasileiras, bem como a triangulação dos dados através de depoimentos de famílias adotantes e de operadores do direito podem possibilitar o aprofundamento da discussão.

Embora com alguns limites, o estudo se mostra relevante no sentido de atentar para a importância de uma fase crucial na formação dos vínculos familiares no processo de adoção. Mais especificamente, revela o papel central da equipe do judiciário no acompanhamento e condução da colocação, ao mesmo tempo em que aponta possibilidades para melhorias na execução dessa etapa e do processo de adoção como um todo.

\section{Referências}

Alonso, E. (2012). Proceso de construcción de una familia adoptiva: relato de dos familias. Papers Infancia_c, (2), 1-26. Recuperado de http://www.infanciacontemporanea.com/documentos/papers/papers_Infancia_c_ alonso2012.pdf

Assis, S. G., \& Farias, L. O. P. (Eds.). (2011). Levantamento nacional das crianças e adolescentes em serviço de acolhimento. São Paulo, SP: Hucitec.

Barboza, H. H. (2000). O princípio do melhor interesse da criança e do adolescente. In Anais do II Congresso Brasileiro de Direito da Família (pp. 201-213), Belo Horizonte, BH.

Bardin, L. (2011). Análise de conteúdo. Lisboa: Edições70.

Brasil. (2009b). Conselho Nacional de Assistência Social. Orientações técnicas: serviços de acolhimento para crianças e adolescentes. Brasília, DF: o autor.

Brasil (2016). Conselho Nacional de Justiça. CNA - Cadastro Nacional de Adoção. Relatórios estatísticos. Recuperado de http://www.cnj.jus.br/cnanovo/pages/publico/index.jsf

Brasil (1990, 16 de julho). Lei No 8.069, de 13 de julho de 1990. Dispõe sobre o Estatuto da Criança e do Adolescente e dá outras providências. Diário Oficial União.

Brasil. (2009a, 4 de agosto). Lei № 12.010, de 3 de agosto de 2009. Dispõe sobre adoção; altera as Leis nos 8.069, de 13 de julho de 1990 - Estatuto da Criança e do Adolescente, 8.560, de 29 de dezembro de 1992; revoga dispositivos da Lei no 10.406, de 10 de janeiro de 2002 - Código Civil, e da Consolidação das Leis do Trabalho - CLT, aprovada pelo Decreto-Lei no 5.452, de 1 o de maio de 1943; e dá outras providęncias. Diário Oficial da União. 
Brasil. (2006). Ministério do Desenvolvimento Social e Combate à Fome. Secretaria Especial dos Direitos Humanos. Plano nacional de promoção, proteção e defesa do direito de crianças e adolescentes à convivência familiar e comunitária. Brasília, DF: o autor.

Carvalho, M. T. M., \& Sampaio, J. R. (1997). A formação do psicólogo e as áreas emergentes. Psicologia: Ciência e Profissão, 17(1), 14-19. https://doi.org/10.1590/S1414-98931997000100003

The Cide of Hammurabi. (1780a.C). Recuperado de http://www.constitution.org/ime/hammurabi.pdf

Costa, L. F., Penso, M. A., Legnani, V. N., \& Sudbrack, M. F. O. (2009). As competências da psicologia jurídica na avaliação psicossocial de famílias em conflito. Psicologia \& Sociedade, 21(2), 233-241. https://doi.org/10.1590/S0102-71822009000200010

Costa, N. R. A., \& Rossetti-Ferreira, M. C. (2007). Tornar-se pai e mãe em um processo de adoção tardia. Psicologia: Reflexão e Crítica, 20(3), 425-434. https://doi.org/10.1590/S0102-79722007000300010

Coulanges, F. (1864). A cidade antiga: estudos sobre o culto, o direito e as instituições da Grécia e de Roma. Rio de Janeiro, RJ: Ediouro.

D’Andrea, A. (2002). O casal adotante. In M. Andolfi (Ed.), L. Kahl, \& G. Menegoz (Trans.), Crise do casal uma perspectiva sistêmico-relacional. (pp. 233-248). Porto Alegre, RS: Artmed.

Fonseca, C. (2006). Da circulação de crianças à adoção internacional: questões de pertencimento e posse. Cadernos Pagu, (26), 11-43. httpa:// doi.org/10.1590/S0104-83332006000100002

Ghesti-Galvão, I. (2008). Intervenções psicossociais e jurídicas no percurso da adoção : a mediação entre o afeto e a lei (Tese de doutorado). Universidade de Brasília, DF.

Gondim, S. M. G. (2002). Perfil profissional e mercado de trabalho: relação com formação acadêmica pela perspectiva de estudantes universitários. Estudos de Psicologia (Natal), 7(2), 299-309. https://doi.org/10.1590/S1413-294X2002000200011

Hamad, N. (2002). A criança adotiva e suas famílias. Rio de Janeiro, RJ: Companhia de Freud.

Huber, M. Z., \& Siqueira, A. C. (2010). Pais por adoção: a adoção na perspectiva dos casais em fila de espera. Psicologia: Teoria e Prática, 12(2), 200-216. Recuperado de http://pepsic.bvsalud.org/scielo.php?script=sci_abstract\&pi$\mathrm{d}=$ S1516-36872010000200014\&lng=pt\&nrm=iso\&tlng=pt

Lago, V. M., Amato, P., Teixeira, P. A., Rovinski, S. L. R., \& Bandeira, D. R. (2009). Um breve histórico da psicologia jurídica no Brasil e seus campos de atuação. Estudos de Psicologia (Campinas), 26(4), 483-491. https:// doi.org/10.1590/S0103-166X2009000400009

Laville, C., \& Dione, J. (1999). A construção do saber: manual de metodologia da pesquisa em ciências humanas. Porto Alegre, RS: Artes Médicas.

Levinzon, G. K. (2014). Tornando-se pais: a adoção em todos os seus passos. São Paulo, SP: Casa do Psicólogo.

Levy, L., Pinho, P. G., \& Faria, M. M. (2009). "Família é muito sofrimento": um estudo de casos de "devolução" de crianças. Psico, 40(1), 58-63. Recuperado de http://revistaseletronicas.pucrs.br/ojs/index.php/revistapsico/article/view/3730

Mahl, F. D., Jaeger, F. P., Patias, N. D., \& Dias, A. C. G. (2012). Enquanto a maternidade não vem: a infertilidade e a pressão social como pano de fundo para a adoção. Pensando Famílias, 16(2), 85-102. Recuperado de https:// www.researchgate.net/publication/275336921_Enquanto_a_Maternidade_Nao_Vem_A_Infertilidade_e_a_Pressao_Social_como_Pano_de_Fundo_para_a_Adocao

Merçon-Vargas, E. A., Rosa, E. M., \& Dell'Aglio, D. D. (2014). Adoção nacional e internacional: significados, motivações e processos de habilitação. Revista da SPAGESP, 15(2), 12-26. Recuperado de http://pepsic.bvsalud.org/ scielo.php?script=sci_arttext\&pid=S1677-29702014000200003\&lng=pt\&nrm=iso\&tlng=pt

Miranda Júnior, H. C. (1998). Psicologia e justiça: a psicologia e as práticas judiciárias na construção do ideal de justiça. Psicologia: Ciência e Profissão, 18(1), 28-37. https://doi.org/10.1590/S1414-98931998000100004

Nabinger, S. B. (2010). Adoção: o encontro de duas histórias. Santo Ângelo: FURI.

NVivo Qualitative Data Analysis Software (Version 10). (2012). Doncaster, Victoria: QSR International Pty Ltd.

Otuka, L. K., Scorsolini-Comin, F., \& Santos, M. A. (2012). Adoção suficientemente boa: experiência de um casal com filhos biológicos. Psicologia: Teoria e Pesquisa, 28(1), 55-63. https://doi.org/10.1590/S0102-37722012000100007 
Paiva, L. D. (2004). Adoção: significados e possibilidades. São Paulo, SP: Casa do Psicólogo.

Reppold, C. T., Chaves, V. P., Nabinger, S. B., \& Hutz, C. S. (2005). Aspectos práticos e teóricos da avaliação psicossocial para habilitação à adoção. In C. S. Hutz. (Org), Violência e risco na infância e adolescência: pesquisa e intervenção (pp. 43-70). São Paulo, SP: Casa do Psicólogo.

Rizzini, I., \& Rizzini, I. (2004). A institucionalização de crianças no Brasil: percurso histórico e desafios do presente. Rio de Janeiro: Ed PUC-Rio; São Paulo: Loyola.

Robson, C. (2002). Real world research: a resource for social scientists and practitioner-researchers (2nd ed.). Malden: Blackwell.

Rovinski, S. R. (2007). Fundamentos da perícia psicológica forense. São Paulo, SP: Vetor.

Ryan, S., \& Whitlock, C. (2008). Becoming parents: lesbian mothers' adoption experience. Journal of Gay \& Lesbian Social Services, 19(2):1-23 httpS:// doi.org/10.1080/10538720802131642

Schneider, J. F., Souza, J. P., Nasi, C., Camatta, M. W., \& Machineski, G. G. (2009). Concepções de uma equipe de saúde mental sobre interdisciplinaridade. Revista Gaúcha de Enfermagem, 30(3), 397-405.

Silva, D. M. P. (2003). Psicologia jurídica no processo civil brasileiro: a interface da psicologia com direito nas questões de família e infância. São Paulo, SP: Casa do Psicólogo.

Silva, P. S. (2015). Os processos de habilitação para adoção segundo técnicos judiciários do Rio Grande do Sul (Dissertação de Mestrado). Universidade Federal do Rio Grande do Sul, Porto Alegre, RS.

Simmel, C. (2007). Risk and protective factors contributing to the longitudinal psychosocial well-being of adopted foster children. Journal of Emotional and Behavioral Disorders, 15(4), 237-249. https://doi.org/10.1177/10634266070150040501

Sprince, J., Hindle, D., \& Shulman, G. (2008). The network around adoption: the forever family and the ghosts of the dispossessed. In D. Hindle, \& G. Shulman. (Orgs), The emotional experience of adoption (pp. 99-114). Abingdon: Routledge.

Sturgess, W., \& Selwyn, J. (2007). Supporting the placements of children adopted out of care. Clinical Child Psychology and Psychiatry, 12(1), 13-28. https://doi.org/10.1177/1359104507071051

Vargas, M. M. (1998). Adoção tardia: da família sonhada à família possível. São Paulo, SP: Casa do Psicólogo.

Weber, L. N. (2003). Pais e filhos por adoção no Brasil: característica expectativas e sentimentos. Curitiba: Juruá.

\section{Patrícia Santos da Silva}

Doutoranda do Programa de Pós-Graduação em Psicologia da Universidade Federal do Rio Grande do Sul, Porto Alegre-RS, Brasil.. E-mail: patis.psico@gmail.com

Luciana Cassarino-Perez

Doutoranda do Programa de Pós-Graduação em Psicologia da Universidade Federal do Rio Grande do Sul, Porto Alegre - RS, Brasil. E-mail: lucicaspe@gmail.com

\section{Jorge Castellá Sarriera}

Professor do Programa de Pós-Graduação em Psicologia da Universidade Federal do Rio Grande do Sul, Porto Alegre-RS, Brasil. E-mail: jorgesarriera@gmail.com

\section{Giana Bitencourt Frizzo}

Professora do Programa de Pós-Graduação em Psicologia da Universidade Federal do Rio Grande do Sul, Porto Alegre - RS, Brasil. E-mail: gifrizzo@gmail.com

Endereço para envio de correspondência:

Rua Antônio Costa, 90. Vista Alegre. CEP: 80820-020.

Curitiba - PR, Brasil. 
Recebido 30/01/2016

Reformulação 04/05/2017

Aprovado 08/06/2017

Received $01 / 30 / 2016$

Reformulated $05 / 04 / 2017$

Approved 06/08/2017

Recebido 30/01/2016

Reformulado 04/05/2017

Aceptado 08/06/2017

Como citar: Silva, P. S., Cassarino-Perez, L., Sarriera, J. C., \& Frizzo, G. B. (2017). A equipe psicossocial na colocação da criança nos processos de adoção. Psicologia: Ciência e Profissão, 37(3), 608-623.

https://doi.org/10.1590/1982-3703000382016

How to cite: Silva, P. S., Cassarino-Perez, L., Sarriera, J. C., \& Frizzo, G. B. (2017). The role of psychosocial team in placement the child for adoption. Psicologia: Ciência e Profissão, 37(3), 608-623. https://doi.org/10.1590/1982-3703000382016

Cómo citar: Silva, P. S., Cassarino-Perez, L., Sarriera, J. C., \& Frizzo, G. B. (2017). El equipo psicosocial en la colocación del niño en adopción. Psicologia: Ciência e Profissão, 37(3), 608-623. https://doi.org/10.1590/1982-3703000382016 